\title{
Constitucionalismo Regresivo: reflexiones en torno al equilibrio ideológico en el Tribunal Constitucional colombiano*
}

\author{
Regressive Constitutionalism: Reflections about the Ideological Balance in the \\ Colombian Constitutional Court
}

Juan Pablo Sarmiento E. ${ }^{\text {a }}$
Universidad del Norte, Colombia
jpsarmiento@uninorte.edu.co
ORCID: https://orcid.org/0000-0002-7303-3300

DOI: https://doi.org/10.11144/Javeriana.vj69.crrt

Recibido: Octubre 17, 2019

Aceptado: Febrero 13, 2020

\section{Resumen:}

En este artículo se argumenta que, con las últimas tres elecciones de magistrados de la Corte Constitucional colombiana, el balance ideológico ha impactado algunas decisiones relativas al reconocimiento de derechos de minorías, la participación ciudadana, al medio ambiente y a la protección de seres sintientes. Este impacto se ha generado a partir de tres estrategias: el neolegalismo y sentencias exhortativas; la creación o ampliación del test de vulnerabilidad y conexidad y la implementación de criterios de ponderación con alteraciones en el peso abstracto de los principios o de los derechos en juego. Así, a partir de la trayectoria de los magistrados y los debates y decisiones judiciales que se han producido desde este nuevo balance, se evidenciarán las principales tensiones materializadas en los ejes jurisprudenciales antes enunciados.

Palabras clave: Neolegalismo y sentencias exhortativas, politización de la justicia, consultas populares, seres sintientes, derechos de los animales, cortes, política.

\begin{abstract}
:
This article argues that, with the last three elections of magistrates of the Colombian Constitutional Court, the ideological balance has impacted some decisions regarding the recognition of minority rights, citizen participation, the environment, and the protection of sentient beings. This impact was generated from three strategies: neolegalism and exhortative sentences, the creation or expansion of the vulnerability and connection test, and the implementation of weighting criteria with alterations in the abstract weight of the principles or rights at stake. Thus, from the magistrates' trajectory and the debates and judicial decisions that have taken place since this new balance, the main tensions materialized in the jurisprudential axes before mentioned will be evident.
\end{abstract}

Keywords: Neo-legalism and exhortative sentences, politicization of justice, popular consultations, sentient beings, animal rights, courts and politics.

\section{Introducción}

La politización de la justicia y la falta de neutralidad de los jueces ha sido el objeto de observación de varias investigaciones y de una nutrida producción intelectual, donde la trayectoria y la agenda política de los jueces permiten modelar ciertas tendencias jurisprudenciales o estrategias de deserción en tiempos de tensiones interinstitucionales ${ }^{1}$, evidencia del asepticismo juridicial y la pretendida neutralidad del silogismo práctico de la corte. Esto nos permite analizar tres formas en las que, quizá, las estrategias de deserción intrasistémicas pueden resultar más difíciles de detectar, en la medida en que logran ocultar la decisión política que subyace a la decisión judicial en el mismo discurso jurídico.

Una de las prácticas intrasistémicas que se identificadas radica en el neolegalismo y las sentencias exhortativas como medio para suspender -indefinidamente- decisiones judiciales sobre asuntos que potencialmente pueden impactar ciertos valores, intereses o generar tensiones interinstitucionales. Esto se ha hecho notable en casos como la eutanasia, el matrimonio igualitario o el reconocimiento del deber de protección a favor de los seres sintientes. 
La anterior muestra cómo la Corte decide postergar una decisión de gran impacto a partir de un desplazamiento de responsabilidad política. La misma suerte tiene la regresión de algunos derechos a partir de la creación del test de conexidad y vulnerabilidad que exigen más elementos fácticos en el caso, que finalmente encuentran en el silogismo práctico un espacio de racionalidad aparente, que contiene una decisión más conservadora en torno al debate constitucional en cuestión. Inclusive, la ponderación, ampliamente defendida como mecanismo para racionalizar el discurso jurídico y como herramienta para la resolución de conflictos entre principios constitucionales termina por aplazar algunas decisiones por cuenta de la disponibilidad de recursos o la consideración de esfuerzos fiscales para la garantía de derechos sociales o de segunda generación.

Estas revisiones jurisprudenciales son constantes, e inclusive se explican a partir de las "líneas de cambio", donde profundos disensos al interior de la Corte o el cambio del balance ideológico del tribunal pueden estimular dichas transiciones jurisprudenciales. El balance actual del caso colombiano, que la Corte quizá no había experimentado antes, invita a realizar una reflexión sobre la manera en que se leen las líneas jurisprudenciales de cambio y las estrategias de deserción intrasistémica. Esta dimensión política puede pasar desapercibida para la comunidad de intérpretes — juristas—, y cuya dimensión jurídica puede ser oscura para la comunidad de lectores —opinión pública-.

Una breve historia de la Corte Constitucional colombiana nos conduce a recordar que, si bien el control abstracto de constitucionalidad tuvo su génesis en la reforma de la Unión Republicana de 1910, con algunos antecedentes en 1886, ha sido eje de profundos disensos, tensiones y ha provocado que, inclusive en épocas de dictadura, se convirtiera en una arena política. Esta inició por la propuesta de reforma constitucional para la creación del Tribunal de Garantías Constitucionales, que terminó por crear la Sala de Negocios Constitucionales en 1956². La Carta de 1991 marca el nacimiento de la Corte Constitucional, pero no con ello el constitucionalismo colombiano.

La Constitución de 1991 intentó remediar el problema de la legitimidad democrática del Tribunal Constitucional por medio de una intermediación de las mayorías parlamentarias, la Presidencia de la República y la rama judicial, en cabeza de la Corte Constitucional y el Consejo de Estado. Así, la elección de los magistrados por parte del Senado de la República parecería lograr la mediación democrática que, de alguna manera, genera una constante crítica conservadora sobre la expresión de poder que subyace a la función de anular las leyes de la República, sin contar con un consenso de las mayorías parlamentarias ${ }^{4}$. Sin embargo, esta mediación de las demás ramas del poder tendría consecuencias en la misma forma en que se ha elegido a los magistrados y los perfiles de quienes finalmente fueron seleccionados.

Como lo demostraron algunas crisis judiciales recientes, la decisión parlamentaria de seleccionar a políticos más que a juristas evidenciaron la expansión de algunas prácticas de redes de poder poco transparentes en la Corte. A manera de ejemplo, el caso del magistrado Jorge Pretelt Chaljub activó una crisis en la Corte que parecía haber eludido por años por cuenta de la corrupción.

De igual forma, las mayorías parlamentarias se dejaron sentir en la composición ideológica de la Corte, donde, paulatinamente, se fue orientando hacia la derecha conservadora, menos sensible ciertos asuntos y más preocupados por los efectos fiscales y morales de sus decisiones. Esta tendencia se ha hecho más notable con respecto a los derechos de minorías, los mecanismos de participación directa, al medio ambiente y a la protección de seres sintientes, en la medida en que se trata de líneas jurisprudenciales en proceso de consolidación y que, además, cuentan con una carga idiosincrática notable. Por lo antedicho, este articulo seleccionará estos ejes jurisprudenciales como ruta orientadora, en la medida en que cuentan con una carga ideológica importante y permiten evidenciar asuntos que pueden provocar tensiones interinstitucionales, como las consultas populares relativas a la minería y explotación de recursos naturales no renovables. Otros asuntos simplemente yacen en el corazón de dilemas idiosincráticos, como el derecho a la interrupción voluntaria del embarazo y la protección de seres sintientes. 
Este artículo se dividirá en dos partes: en primer lugar, se realizarán algunas reflexiones en torno a la transición en la composición ideológica de los magistrados que han sido elegidos en la Corte Constitucional colombiana, a partir de una validación por expertos sobre la trayectoria y la posición ideológica que han ostentado, para luego revisar los debates que se abrieron y que permiten evidenciar la carga ideológica en las decisiones adoptadas y los salvamentos de voto que se realizaron en cada una de las decisiones tomadas en los ejes jurisprudenciales selecionados.

\section{El (des)balance ideológico de la Corte Constitucional a partir del diseño institucional}

Como se mencionó, el control constitucional en Colombia nació en 1910, aunque tuvo algunos antecedentes $^{5}$. Desde la reforma constitucional de 1910, dicha función fue encargada a la Corte Suprema de Justicia hasta la Carta de 1991, cuando nació la Corte Constitucional. Empero, en términos de control de constitucionalidad mostró una connatural propensión a provocar tensiones con las otras ramas del poder en distintos momentos. Quizás la más notable ocurrió con la dictadura de Gustavo Rojas Pinilla y que, inclusive, desembocó en la creación de la Sala de Negocios Constitucionales, que pretendía dominar la composición de dicha Sala por medio de un sistema de nominación y selección presidencial ${ }^{6}$.

En efecto, el control de constitucionalidad de las leyes genera una tensión política connatural y ampliamente estudiada desde todos los espectros ideológicos, donde se pueden constatar diversas críticas enfocadas a la falta de representatividad democrático-política de los magistrados que tienen asiento en la Corte $^{7}$. Sin embargo, también se encuentran importantes argumentos que defienden la disciplina y la necesidad de contar con magistrados que asuman decisiones racionales, desprovistas de consideraciones políticas, más próximos a la idealización sobre el rol de los jueces ${ }^{8}$.

Al final, el debate constitucional de 1991 y la posterior reforma de 2015 arribó a un diseño institucional que parecería mediar entre la legitimación democrática y la racionalidad jurídica. Por una parte, intentó garantizar la mediación de las ramas del poder más representativas en términos de elección popular, como lo son el presidente de la República y el Senado de la República y, a su vez, garantizar la mediación de la misma rama judicial por medio del Consejo de Estado y la Corte Suprema de Justicia. Así, la Carta Política establece que los miembros de la Corte Constitucional tienen períodos individuales de 8 años, y son elegidos por el Senado de la República, de ternas enviadas por el presidente de la República, la Corte Suprema de Justicia y el Consejo de Estado. La ley estatutaria 270 de 1996 estableció como criterio adicional de selección que el Senado considerara la diversidad en la especialidad jurídica de los magistrados.

Este último ingrediente fue reforzado por el Acto Legislativo 2 de 2015, al mantener tres condiciones habilitantes mínimas: ser colombiano de nacimiento y ciudadano en ejercicio, ser abogado y no haber sido condenado por sentencia judicial a pena privativa de la libertad, excepto por delitos políticos o culposos. El mismo Acto Legislativo extendió el requisito de experiencia, pasando de exigir diez años de ejercicio, a quince años en cargos en la Rama Judicial o en el Ministerio Público, o haber ejercido, con buen crédito, la profesión de abogado o la cátedra universitaria en disciplinas jurídicas en establecimientos reconocidos oficialmente por el mismo tiempo.

Con esta fórmula institucional, la Corte Constitucional quedaría compuesta por miembros que son elegidos por el Senado, de listas elaboradas por la rama judicial y la ejecutiva. Esta mediación del órgano legislativo y la nominación proveniente de las otras ramas parecería fortalecer la legitimidad de la Corte, pero, como se demostrará a continuación, puede haber tenido un impacto en el balance ideológico.

Para realizar esta caracterización, se han propuesto tres categorías: Centro Liberal (CL, Centro progresista (CP y Conservador Centro Derecha (CCD. Si bien el espectro ideológico que puede representar a los magistrados puede ser mucho más variado, se ha reducido a estas tres alternativas en función de los ejes 
jurisprudenciales seleccionados. De esta forma, se han clasificado como magistrados de centro y liberales aquellos orientados al lado de los derechos fundamentales y libertades públicas, restrictivo en derechos de segunda generación y distribución de la riqueza, y de moderada intervención del juez. Se agruparon como magistrados centro progresistas a aquellos más amplios en activismo judicial y especialmente activos en el marco de la redistribución e intervención económica y orientados hacia la intervención relativa a seres sintientes y derechos de las minorías. Por último, se han enmarcado a otros magistrados como conservador centro derecha que defienden el liberalismo económico, censuran el activismo judicial y se inclinan hacia el revisionismo de los avances en la interrupción voluntaria del embarazo, eutanasia, derechos de las parejas del mismo sexo, de la protección de seres sintientes y de la participación ciudadana.

Para representar la variación ideológica en la composición de la Corte validada por expertos en derecho e historia constitucional, así como magistrados auxiliares que han trascendido los períodos de los magistrados titulares presentamos las siguientes tendencias (figuras 1 a 4 ).



FIGURA 1.

Primera Corte 1991-2001

Fuente: elaboración propia

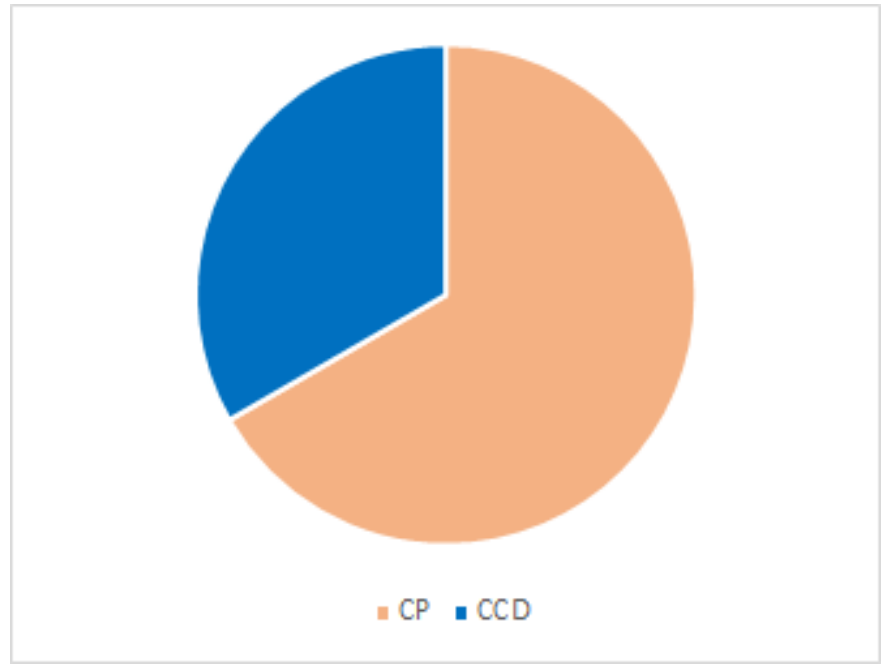

FIGURA 2.

Segunda Corte 1998-2009

Fuente: elaboración propia 


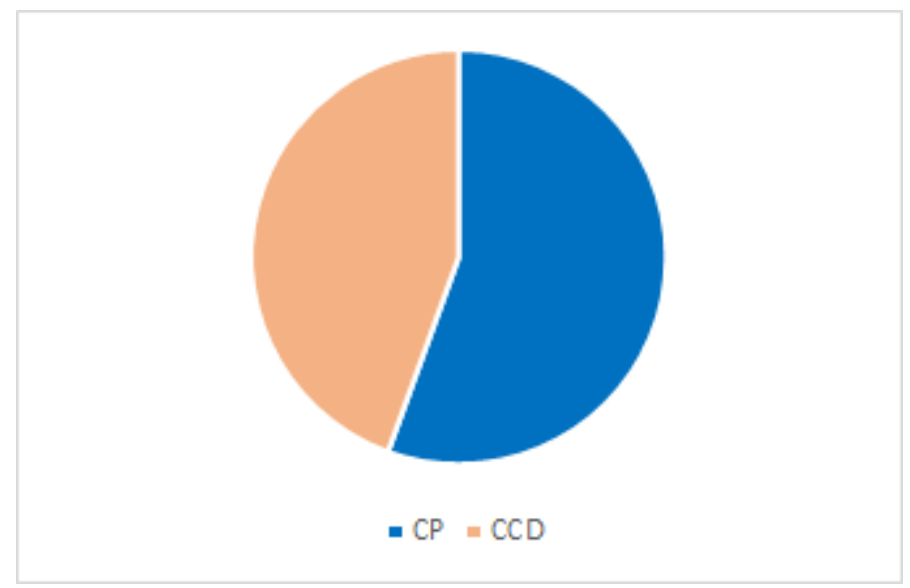

FIGURA 3.

Tercera Corte 2004-2017

Fuente: elaboración propia

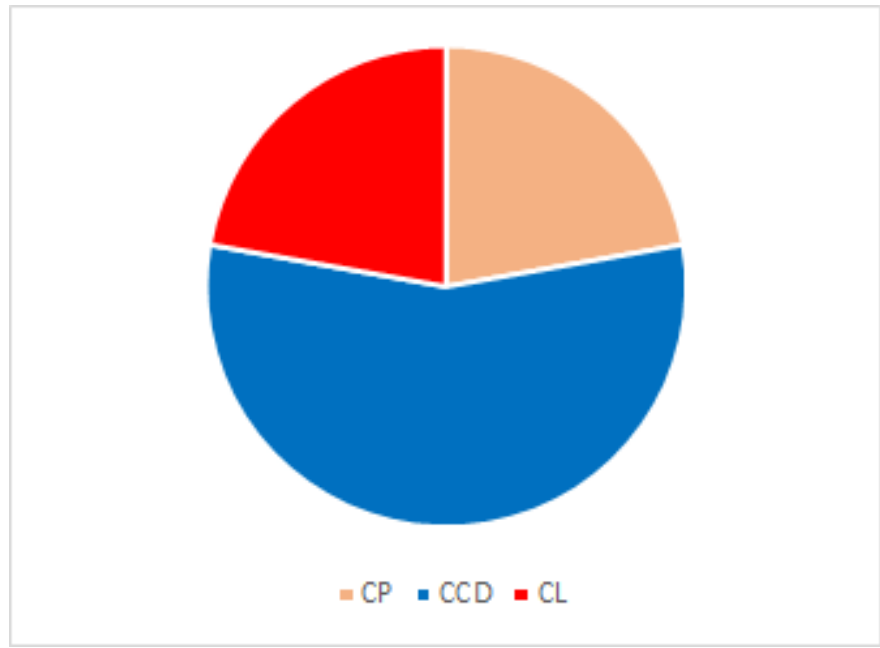

FIGURA 4.

Cuarta Corte 2012-2025

Fuente: elaboración propia

Una línea de tiempo ayuda a ilustrar el balance ideológico que ha sufrido la Corte Constitucional (Figura 5). 


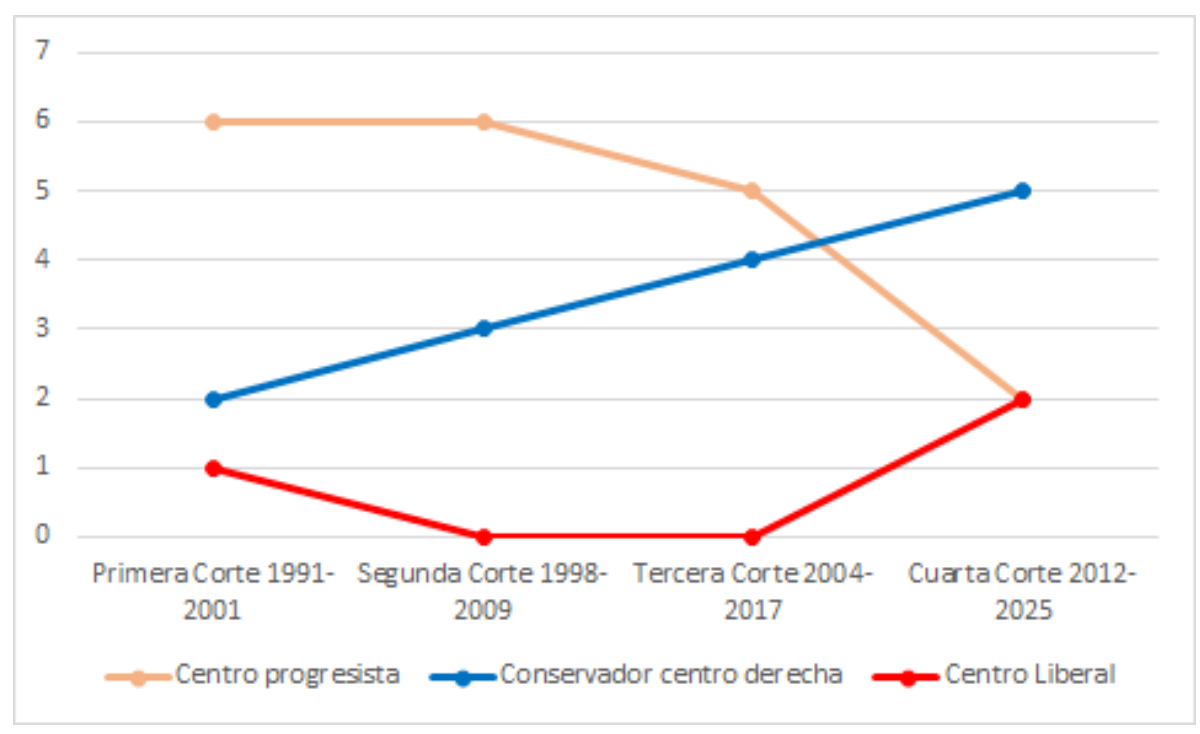

FIGURA 5.

Tendencia ideológica en las cuatro Cortes

Fuente: elaboración propia

Ahora bien, la anterior caracterización no deja de lado las críticas al "minimalismo judicial", que censura el papel de un juez o magistrado de sus trayectorias o de su postura política por medio de la microhistoria. En efecto, no se quiere dejar de lado las "cascadas informativas"10, y la más relevante, la "cascada de precedente", usuales ante interpretaciones genuinas con una capacidad estabilizadora notable y fuente de subreglas más diáfana que conducen a la reproducción de la decisión antes adoptada por el mismo órgano, independientemente del balance político o ideológico del aparto judicial. Entonces, esta propuesta censura la visión netamente actitudinal, pero enriquece el alcance tanto del precedente como de su relativa fuerza vinculante. Empero, los ejes jurisprudenciales seleccionados a continuación carecen de consistencia y con ello permiten que los magistrados construyan una decisión al filtrar en ella una posición idiosincrática específica en el marco de un desarrollo jurisprudencial "pretoriano", del cual facilita maniobras políticas poco neutrales, pero, en algunos casos, reformuladoras o novedosas.

Así, estos "ejes jurisprudenciales" han sido seleccionados porque son capaces de producir tensiones interinstitucionales, y segundo, porque carecen de estabilidad. Cada uno de los temas seleccionados tiene la capacidad de producir decisiones judiciales que tienen repercusiones en los demás poderes o que impactan en asuntos con una importante carga moral o social. Estos muestran que la trayectoria jurisprudencial adapta los significados atribuidos a la Constitución en diferentes entornos políticos y dan cuenta de la configuración de un sistema jurídico, propio de una tensión interinstitucional o un problema social con una importante carga moral ${ }^{11}$.

\section{Ejes jurisprudenciales y estrategias de deserción intrasistémicas}

Las más recientes decisiones de la Corte Constitucional dan cuenta de las estrategias de deserción y la reorientación de ciertas líneas jurisprudenciales amparadas en tres estrategias discursivas, propias del sistema jurídico: el neolegalismo y sentencias exhortativas; la creación o ampliación del test de vulnerabilidad y conexidad; y los criterios de ponderación con alteraciones en el peso abstracto de los principios o de los derechos en juego.

Como se expuso previamente, se han acogido tres ejes jurisprudenciales que evidencian las citadas estratégicas. Estos ejes jurisprudenciales son la interrupción voluntaria del embarazo, la participación 
ciudadana, la protección del medio ambiente y de seres sintientes. Para este propósito se presentarán las líneas jurisprudenciales, combinando el análisis estático y dinámico de precedentes ${ }^{12}$, para hacer hincapié en las razones de cambio en la decisión. Igualmente, se analizarán los salvamentos de voto, con especial atención a lo dicho por las posiciones minoritarias, que den cuenta de la tensión ideológica que pretende demostrar este trabajo.

\section{Consultas populares, minería e hidrocarburos ${ }^{13}$}

$\mathrm{Al}$ igual que en el resto de las economías donde predomina el sector primario, Colombia encuentra una importante dependencia en la explotación de hidrocarburos y de minerales. Por esta razón, distintos grupos ambientalistas y movimientos sociales presionaron a las autoridades locales de los municipios para la realización de consultas populares para que se pronunciaran en contra de la explotación de hidrocarburos y minería en su territorio. Lo anterior generó importantes inquietudes en el Gobierno Nacional - Ministerio de Minas y Energía- y en las empresas explotadoras de recursos naturales no renovables.

Luego de varias de estas consultas, vino la intervención de la Corte Constitucional en sede de Tutela y de Acciones Públicas de Inconstitucionalidad. Las primeras, en defensa del derecho fundamental a la participación política y, la segunda, en el marco de diversas acciones presentadas en contra del Código de Minas. Las principales sentencias que emitió la Corte fueron la C- 123 de 2014, la C-273 de 2016, la C-035 de 2016, la T-445 de 2016, la T-121 de 2017 y las sentencias que centrarán nuestro estudio son la SU-095 de 2018 y la C-053 de 2019. Los primeros fallos enunciados la Corte determinó que los municipios sí tienen competencia para promover consultas populares cuando se busque realizar actividades de exploración y explotación minera. En contraposición, en la Sentencia SU-095 del 2018 la Corte Constitucional determinó que, si bien las entidades territoriales son titulares del principio de autonomía territorial, las consultas populares no pueden ser utilizadas para prohibir o detener actividades de extracción ni detener proyectos extractivos. En el mismo sentido, la Sentencia C-053 de 2019 decidió la constitucionalidad de la Ley 136 de 1996, que establecía un mecanismo de participación directa forzosa a través de la consulta popular, cuando el desarrollo de proyectos de naturaleza turística, minera o de otro tipo, amenazara con crear un cambio significativo en el uso del suelo, que diera lugar a una transformación en las actividades tradicionales de un municipio. Allí, la Corte definió si se trata de un caso de inconstitucionalidad formal derivada de la reserva de la ley orgánica en relación con la asignación de competencias entre la Nación y las entidades territoriales y si también desconoció dicha reserva de la estatutaria con respecto al establecimiento de un mecanismo de participación ciudadana.

En los fallos C-123 de 2014, C-273 de 2016, C-035 de 2016, T-445 de 2016 y T-121 de 2017, la Corte Constitucional sostuvo que las autoridades nacionales tenían la obligación de concertar con las autoridades territoriales la adopción de medidas a fin de proteger al medio ambiente y las comunidades, teniendo en cuenta los daños que puede generar la actividad de exploración y explotación de hidrocarburos en los municipios o distritos en los que se realice. Así mismo, en dicho precedente, la Corte reitera el deber de armonizar el principio unitario con la autonomía de las entidades territoriales. Por su parte, en las sentencias de constitucionalidad 123 de 2014 y 273 de 2016, la norma demandada es el artículo 37 de la Ley 685 de 2010, con diferentes cargos en cada una de dichas providencias, mientras que en la sentencia C-035 de 2016 son demandados los artículos 108 de la Ley 1450 de 2011, el artículo 20 de la Ley 1753 de 2015, parcialmente los artículos 49 y 50, parcialmente los artículos 51 y 52 de la Ley 1753 de 2015 y el artículo 173 de esta última. Con todo, la demanda contra el artículo 108 de la Ley 1450 de 2011 y el artículo 20 de la Ley 1753 de 2015 fueron los más relevantes, en la medida en que el Alto Tribunal decidió su constitucionalidad bajo el entendido del desconocimiento de los principios de autonomía territorial, coordinación, concurrencia y subsidiariedad. 
A manera de resumen, la anterior línea jurisprudencial (tabla 1) podría enunciarse en la siguiente pregunta: ¿La consulta popular podría evitar la realización de actividades mineras sobre el suelo administrado por el municipio?

TABLA 1

\section{Línea jurisprudencial sobre consultas populares y actividades mineras}

\begin{tabular}{|c|c|c|}
\hline $\begin{array}{l}\text { La consulta popular Sí puede } \\
\text { evitar la realización de } \\
\text { actividades mineras sobre el } \\
\text { suelo del municipio }\end{array}$ & 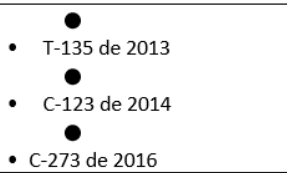 & $\begin{array}{l}\text { La consulta popular No puede } \\
\text { evitar la realización de } \\
\text { actividades mineras sobre el } \\
\text { suelo del municipio }\end{array}$ \\
\hline & 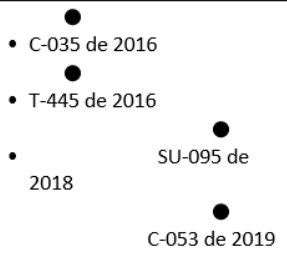 & \\
\hline
\end{tabular}

En sentencia T-445 de 2016, que resolvía una acción de tutela presentada en contra de una sentencia que declaró inconstitucional la pregunta sobre "la conveniencia o no de las actividades de explotación, exploración, tratamiento, lavado de producto de la explotación minera" ${ }^{14}$ que se iba a formular en una consulta popular en el municipio de Pijao por considerar que este último carecía de las competencias para excluir, de manera autónoma y aislada de la administración nacional, las actividades mineras en ciertas zonas del suelo del municipio. Al dirimir este conAicto, la Corte sentó su posición de manera certera. En primer lugar, dejó claras no sólo las sentencias C-123 de 2014 y la C-035 de 2016, sino las numerosas consecuencias negativas que acarrea la actividad minera para la población de la zona donde se realice y que fueron estudiadas en por la Corte en los anteriores fallos, como lo son el aumento en la demanda de servicios, y la alteración de las costumbres de los pobladores locales por la llegada de población migrante. En los anteriores fallos, la Corte aseveró que:

"En algunas poblaciones los impactos sociales han implicado, incluso, deserción escolar en jóvenes que ven la minería y los recursos que ésta provee como única salida a la pobreza. Igualmente, el aumento de la drogadicción, la prostitución, la violencia sexual, las enfermedades de transmisión sexual y el madresolterismo no deseado han coincidido con la llegada de los mineros a un municipio o distrito que no se encuentre preparado para recibirlos." ${ }^{15}$

En cuanto a lo económico, en los citados precedentes la Corte se pronunció acerca de los efectos colaterales que este tipo de actividad traería en los siguientes términos:

"La economía pecuaria o agrícola suele ser desplazada por la minera, afectando el nivel de seguridad alimentaria que existía antes del inicio de la actividad minera [...] Igualmente, al aumentar la población aumenta el costo de vida debido a la demanda de servicios para los cuales no suele existir una oferta adecuada, afectando a la población local que no se dedica a la minería. Esto sin duda repercute en el desarrollo económico de los municipios y afecta la función de planeación del mismo, competencia de los municipios de acuerdo con el tantas veces mencionado artículo 311 de la Constitución."16

A nivel ecológico, reconoce las siguientes consecuencias:

"En tanto la exploración y explotación minera exige el empleo de ingentes cantidades de agua, implicará la posible afectación de la fuente de donde sea tomada el agua requerida, así como del lugar en donde sean vertida el agua utilizada; la actividad minera precisará, igualmente, de un sitio adecuado para el depósito de los materiales necesarios para su realización, la construcción de vías de acceso, la creación de una infraestructura que permita disponer de los residuos que no se utilicen, etc." 17

La Corte concluye tajantemente que "es claro que la actividad minera tiene la potencialidad de afectar el medio ambiente de los municipios receptores a los cuales llega" ${ }^{18}$. En otras palabras, la realización de un proyecto de exploración o explotación minera conlleva a una cantidad significativade secuelas gravosas para la población del municipio donde es llevada a cabo.

En la Sentencia C-123 de 2014, al evaluar la constitucionalidad del artículo 37 de la ley 685 de 2001, la Corte Constitucional manifiesta que la disposición acusada, de ser interpretada de forma gramatical, anularía 
la posibilidad de la reglamentación de los municipios para determinar los usos del suelo, en lo atinente a zonas de exploración y explotación minera, al ser contrario a lo establecido en los artículos 287 (numeral 1), 311 y 313 (numeral 7) de la Constitución.

En la Sentencia T-294 de 2014, la Corte se refiere al tema de la justicia ambiental, en el cual explica que un tratamiento justo es, entre otras cosas, aquel en donde

"ningún grupo de personas, incluyendo los grupos raciales, étnicos o socioeconómicos, debe sobrellevar desproporcionadamente la carga de las consecuencias ambientales negativas como resultado de operaciones industriales, municipales y comerciales o la ejecución de programas ambientales y políticas a nivel estatal, local o tribal”.

Teniendo en cuenta la larga lista de consecuencias nocivas ya mencionadas, es posible concluir que supeditar el rechazo de la práctica de actividades mineras a la decisión exclusiva de la administración nacional desconoce el concepto de la justicia ambiental, concepto al que la misma Corte ha dado relevancia. La Corte ahonda en el tema diciendo que:

"el Estado o los particulares no pueden afectar el ambiente natural de manera indiscriminada, sin tener en cuenta las circunstancias propias del sitio y de sus pobladores. Estas circunstancias especiales son las que impiden, por ejemplo, que se construya una planta de embotellamiento de agua mineral en la única fuente de abastecimiento de un poblado, o que se construya una planta de producción de asfalto en frente de un hospital para dolientes pulmonares, o una fábrica de productos químicos en medio de una bahía de pescadores". ${ }^{19}$

Seguido de esto, la Corte también hace hincapié en la participación ciudadana de aquellos habitantes de los municipios donde se realiza el proyecto minero de la siguiente manera: para garantizar que la justicia social ambiental no sea anulada o menoscabada bajo el rótulo (sicde "desarrollo", debe garantizarse la participación de los afectados en el mayor nivel posible, bien sea que estos tengan una forma ancestral de interrelacionarse con su entorno (pueblos indígenas o tribales) o solo sean sujetos vulnerables que puedan verse afectados por una intervención económica a gran escala. En este sentido la Sentencia T-135 de 2013 afirmó lo siguiente:

"El derecho a la participación de los grupos de población potencialmente afectados por causa de un proyecto de "desarrollo", constituye una de las formas en las que el Estado puede y debe prevenir que visiones generales del "interés general" generen graves afectaciones en los derechos de las personas. Al ejecutar un megaproyecto, el campesino, el jornalero o el tradicional habitante de una región afectada, se encuentra en un verdadero estado de indefensión frente al empresario o dueño del proyecto. Solo con el adecuado ejercicio de la participación podrá evitar que se lesionen sus derechos".

la Corte, de la mano del concepto de justicia social, deja claro que es primordial la participación de la población que lleve la mayor parte, si no todo, del impacto ambiental, económico, social y cultural que causan las actividades mineras. La importancia que la Corte le da a la participación ciudadana es tal, que para esta "se debe destacar que la adecuada participación en las decisiones que afectan a los habitantes de un municipio debe ser un imperativo necesario para dotar de legitimidad las decisiones de la administración sobre la materia". ${ }^{20}$

Sobre los mecanismos que deben usarse para garantizar la participación de esta población, para la Corte:

"no hay ninguna objeción para considerar la validez constitucional de mecanismos tales como el referendo, en todas sus formas, el plebiscito, la consulta popular, la iniciativa normativa, el cabildo abierto. No existe ninguna objeción para afirmar que estos no pueden ser unos mecanismos eficaces para realizar derechos de participación en la esfera ambiental”.

En particular, respecto de las consultas populares, la Corte concluye que:

"es claro que la consulta popular de carácter municipal es un mecanismo de participación que le permite a los habitantes manifestar su opinión de cara a un aspecto específico,y en esa medida el componente ambiental no está excluido de su órbita de competencias." 22

Incluso, la Corte exhorta a los tribunales encargados de revisar la constitucionalidad de la pregunta a formular en la consulta popular a "limitarse a ejercer el control constitucional de la manera más garantista 
posible al derecho a la participación ciudadana" ${ }^{23}$. Finalmente, en lo que respecta al tema de quién es competente para decidir acerca de las actividades mineras, la Corte no dejó duda alguna pues advirtió que:

\begin{abstract}
"Las comunidades locales no tienen la potestad legal de decidir qué se hace con el subsuelo, porque ese es del Estado que, en este caso, es unitario. Pero como sí tienen la facultad constitucional de ordenar el uso del suelo, entonces poseen el derecho a intervenir en los eventos en los que el Estado toma la decisión de favorecer una actividad minera en su territorio (...) Por la inseparable relación entre las actividades extractivas del subsuelo y el suelo, de nada serviría que un municipio pueda regular el suelo si una directriz del Gobierno central será la que disponga sobre los usos del subsuelo. (...) Es así como se evidencian los principios de Estado Unitario y autonomía territorial. A partir del principio de Estado unitario consagrado en el artículo $1^{\circ}$ de la Constitución, Colombia es un estado unitario y es en desarrollo de este principio que hay una centralización política que implica la existencia de competencias centralizadas para la toma de algunas decisiones como lo es el desarrollo de la actividad minera, es por ello que les corresponde a las autoridades nacionales en qué zonas se desarrolla dicha actividad. Ahora esta unidad nacional no resulta absoluta por cuanto existe en nuestro ordenamiento jurídico otro principio que es el de autonomía territorial". ${ }^{24}$
\end{abstract}

Con respecto al principio de autonomía territorial cabe manifestar que la corte reconoce que el núcleo esencial del principio de autonomía territorial implica que los municipios: "i se gobiernen por autoridades propias; ii ejerzan las competencias que les correspondan; iii administren sus recursos y establezcan tributos que permitan el cumplimiento de sus funciones; y iv participen en las rentas nacionales" 25 . Estos dos principios se contraponen, pero existen diferentes instrumentos desde la Constitución que concilian ambos principios, estos son, en palabras de la Corte Constitucional, (i las facultades de las entidades territoriales, (ii la asignación de competencia al Congreso para regular el grado de autonomía de las entidades territoriales y los (iii principios de coordinación, concurrencia y subsidiariedad entre la Nación y los entes territoriales ${ }^{26}$. En dicha sentencia la Corte reconoce que, de dar interpretación gramatical al artículo cuya constitucionalidad se evalúa, se vulneraría el núcleo esencial del principio de autonomía de los entes territoriales, más específicamente con respecto a las garantías de gobernarse por autoridades propias y ejercer las competencias que le corresponden.

La Corte sostiene en su jurisprudencia que el núcleo esencial del principio de autonomía es indisponible debido a que es la expresión de dos principios constitucionales de gran categoría como lo son la consagración del municipio como la entidad fundamental del ordenamiento territorial y el ejercicio de las competencias asignadas conforme a los principios de coordinación, concurrencia y subsidiariedad. Así, la Corte establece que, si bien la actividad minera ha sido reconocida como de utilidad pública, el anular la posibilidad de reglamentación de los municipios para determinar los usos del suelo con respecto a la posibilidad de excluir zonas de la actividad de exploración y explotación minera (teniendo en cuenta las grandes afectaciones que puede generar esta actividad en un municipio, atentaría contra el principio de autonomía territorial y, a su vez, contra los principios de concurrencia, coordinación y descentralización que la Constitución reconoce a las entidades territoriales, dentro de las cuales están los municipios.

El principio de concurrencia implica que la actividad del Estado debe cumplirse con la participación de los distintos niveles de la administración. Por otra parte, el principio de coordinación parte de las competencias concurrentes entre distintas autoridades del Estado, por lo que tanto la atribución como el ejercicio de las competencias se debe hacer de manera que la acción de las autoridades del Estado resulte complementaria y conducente a la realización de los fines estatales. Es así que en la Sentencia C-123 de 2014 la Corte Constitucional reconoce que en virtud de los principios anteriormente mencionados, "la Nación no puede ser el único nivel competencial involucrado en decisiones con respecto a la explotación y exploración minera, debiendo también incluirse de forma activa y eficaz a los municipios y distritos afectados" 27 y declara exequible el artículo en mención bajo la condición de que las autoridades territoriales y nacionales concerten las medidas necesarias para evitar las afectaciones que se puedan generar a nivel municipal o distrital con las actividades de explotación y exploración minera.

En la Sentencia C-035 de 2016 el problema jurídico que encuentra la Corte Constitucional tiene que ver con el artículo 20 de la Ley 1753 de 2015, en donde se pregunta: ¿al facultar a una entidad del orden 
nacional para delimitar las reas de Reserva Estratégica Minera, se restringe la autonomía constitucional de las entidades territoriales? La Corte constitucional, al igual que en la Sentencia C-123 de 2014 - y en los mismos términos-, resuelve declarar la exequibilidad del artículo de forma condicionada bajo el entendido que se debe permitir la participación de los municipios.

Con todo, el giro argumentativo consignado en la Sentencia SU-095 de 2018 es profundo, pues la Corte considera que el tribunal administrativo del Meta incurrió en un defecto sustantivo, lo cual es una violación directa de la Constitución y un desconocimiento del precedente judicial. En dicha sentencia se sostiene que "la Corte Constitucional ha señalado de forma expresa la imposibilidad de realizar consultas populares sobre asuntos ajenos a las competencias de las autoridades territoriales o sobre aquellos que tengan incidencia en los asuntos nacionales o departamentales". Por ello, le corresponde a la Corte hacer un análisis con respecto a si la consulta popular cumple con lo que ha sido llamado como límites competenciales.

Luego de dicho análisis la Corte concluye que la propiedad de los recursos del subsuelo recae en cabeza del Estado y que el Tribunal Administrativo del Meta no tiene en cuenta las competencias radicadas en cabeza del Gobierno Nacional central en la materia. Con lo anterior la Corte limita el principio de autonomía territorial del cual había reiterado tener un núcleo esencial que es inviolable y, a su vez, limita los principios de concurrencia, coordinación y descentralización. Esto, sin mencionar, que la Corte contraría uno de los pilares de la Constitución de 1991 como la democracia participativa. Por otra parte, la Corte manifiesta la existencia de un precedente constitucional, dentro del cual están las sentencias C-149 de 2010, C-237 de 2016, C-395 de 2012, entre otros. Pese a ello, no existe una relación entre dichos pronunciamientos y el caso en cuestión.

La Corte deduce que en la sentencia proferida por el Tribunal Administrativo del Meta no tuvo en cuenta las disposiciones constitucionales en materia de explotación del subsuelo y de recursos naturales no renovables que confieren competencias al Estado en sentido amplio y han sido desarrolladas en el ordenamiento jurídico mediante leyes y diversos actos administrativos. Estos últimos definen una normativa a nivel nacional para el sector minero energético, regulan las regalías a través del Sistema General de Regalías y crean una institucionalidad y estructura centrada en el Gobierno Nacional central. Sin embargo, la Corte ignora lo que había manifestado en otras sentencias con respecto a que las autoridades competentes a nivel nacional debían acordar con las autoridades territoriales todas aquellas medidas necesarias para evitar la afectación de los habitantes y de los territorios en los que se llevara a cabo la exploración y explotación minera.

Ahora bien, la Sentencia C-053 de 2019 se centra en un aspecto más procesal y de competencia que en un argumento de fondo. En dicho fallo, la Corte señaló que la Ley 136 de 1994 fue tramitada como ley ordinaria y su tema general se refería a la adopción de normas tendientes a modernizar la organización y el funcionamiento de los municipios. No obstante, al hacer un análisis del artículo $33^{28}$ se observa que la materia regulada se refiere a los casos en que, por expresa disposición del artículo 105 de la Constitución Política - que consagra la facultad general del gobernador y alcalde para realizar consultas populares para decidir sobre asuntos de competencia del respectivo departamento o municipio-, se requiere la aprobación a través de una ley orgánica.

La Corte, sin embargo, tomó una decisión de fondo crucial. En el fallo determinó que una ley, cualquiera que sea su jerarquía, no puede imponer la obligación en cabeza de los gobernadores y alcaldes de adelantar una consulta popular cuando el desarrollo de proyectos amenace con crear un cambio significativo en el uso del suelo, pues esto desconocería el artículo 105 de la Constitución. Para este fallo, la Constitución "consagra una posibilidad, no una orden, en cabeza de las autoridades municipales quienes son las llamadas a decidir sobre la conveniencia y la necesidad de su realización”. La misma sentencia hace énfasis y reitera lo señalado en la sentencia C-053 de 2019, en que la realización de una consulta popular debe considerar la concurrencia de competencias no sólo locales, sino también nacionales como es el caso de la explotación de recursos naturales no renovables, de manera que, como expone la Corte, las consultas populares sólo “están circunscritas a asuntos de competencia del respectivo departamento o municipio". En este asunto, los magistrados Alejandro Linares y Diana Fajardo presentaron aclaración de voto, pero apoyaron la decisión. 
Con los dos últimos pronunciamientos, la Corte desconoce su precedente y reduce notablemente los derechos de las comunidades a manifestarse sobre los proyectos de exploración y explotación de recursos naturales no renovables mediante las consultas populares. Con las sentencias SU-095 del 2018 y C-053 de 2019 se vacían las competencias de los municipios en la definición de los usos del suelo y se radican en las entidades nacionales, reforzando la centralidad política y administrativa del país. Ahora bien, con este giro jurisprudencial, la Corte ha combinado dos argumentos intrasistémicos notables: primero, la falta de competencia del legislador para ordenar las consultas populares en mecanismos de participación directa y, segundo, en la Sentencia SU-095 de 2018, la Corte, en una decisión neolegalista, exhortó al Congreso de la República para definir uno o varios mecanismos de participación ciudadana y los instrumentos de coordinación y concurrencia "nación-territorio". Adicionalmente, optó por exigir a los alcaldes de los municipios del país para que, en el marco de sus competencias de ordenamiento territorial, tengan en cuenta los principios de coordinación y concurrencia con las autoridades nacionales.

\section{Seres sintientes y de la protección a la naturaleza ${ }^{29}$}

A partir de demandas de inconstitucionalidad promovidas en defensa de los derechos de los animales principalmente en torno a la práctica de actividades de tauromaquia y peleas de gallos- han provocado el pronunciamiento judicial, con verdaderos vaivenes, propio de las tensiones que se generan entre el reconocimiento de tradiciones y prácticas culturales y la protección de la fauna y el reconocimiento de los animales como "seres sintientes" en Colombia. No obstante, en este eje jurisprudencial, los disensos se dejaron ver en la más reciente sentencia que, además, recoge lo avanzado en los fallos que se pronunciaron en los últimos ocho años. Aquí, los fallos más relevantes fueron las sentencias C-1192 de 2005, C-115 de 2006, C-367 de 2006, C-666 de 2010, C-889 de 2012, C-283 de 2014, C-467 de 2016, C-041 de 2017, Auto 547 de 2018 y SU-056 de 2018. La siguiente tabla permitiría identificar cómo se orientó la línea jurisprudencial hacia una postergación de la decisión sobre la materia.

¿Las corridas de toros, las corralejas, las becerradas, las novilladas, el rejoneo, las tientas y las riñas de gallos son excepciones proporcionales y razonables al deber de protección de los seres sintientes que sólo se pueden restringir por el legislador?

TABLA 2

Línea jurisrpudencial sobre corridas de toros y protección animal

\begin{tabular}{|c|c|c|c|}
\hline $\begin{array}{l}\text { Las corridas de toros y } \\
\text { demás expresiones } \\
\text { culturales son } \\
\text { excepciones } \\
\text { proporcionales y } \\
\text { razonables al deber de } \\
\text { protección animal que } \\
\text { sólo se pueden restringir } \\
\text { por el legislador }\end{array}$ & $\begin{array}{l}\text { C-1192 de } 2005 \\
\text { Auto } 547 \text { de } 2018 \\
\bullet \\
\text { SU-056 de } 2018\end{array}$ & C-041 de 2017 & $\begin{array}{r}\text { Las corridas de toros } \\
\text { y demás expresiones } \\
\text { culturales no son } \\
\text { excepciones } \\
\text { proporcionales y } \\
\text { razonables al deber } \\
\text { de protección animal } \\
\text { que sólo se pueden } \\
\text { restringir por el } \\
\text { legislador }\end{array}$ \\
\hline
\end{tabular}

La sentencia C-1192 de 2005 conoció de una demanda de inconstitucionalidad contra los artículos $1 .^{\circ}$ (espectáculos taurinos como expresión artística), 2. (aplicación general del reglamento), 22 (ingreso de menores de 10 años, comportamiento durante la lidia) y 80 (fomento de fiestas taurinas) parciales de la Ley 916 de 2004 "Por la cual se establece el Reglamento Nacional Taurino". En esta sentencia, la Corte reconoció que las corridas de toros, las corralejas, las becerradas, las novilladas, el rejoneo, las tientas y las riñas de gallos, son una tradición artística y cultural de Colombia. Por esta razón, protegió dichas expresiones culturales a pesar de suponer tratos crueles con los animales. 
Por su parte, la sentencia C-115 de 2006 resolvió una demanda de inconstitucionalidad contra los artículos 1, 2y 12 (niños torerillos); los artículos 22 y 26 (espectáculos presididos por alcaldes); el artículo 31 (ganadería producto de alto interés nacional) y, nuevamente, el artículo 80 de la ley 916 de 2004. En este caso, la Corte declaró la constitucionalidad de la expresión "la regulación de la preparación, organización y desarrollo de los espectáculos taurinos y de las actividades relacionadas con los mismos" ${ }^{30}$, contenida en el artículo $1^{\circ}$ de la ley 916 de 2004. Igualmente, confirmó lo resuelto en la Sentencia C-1192 de 2005, en relación con las expresiones "los espectáculos taurinos son considerados como una expresión artística del ser humano". No obstante, declaró la constitucionalidad de la expresión "la que forman con niños torerillos [...] del mundo taurino", del artículo 12 de la Ley 916 de 2004, salvo la expresión "profesionales ... cuando su precocidad permite su explotación económica” la cual fue declarada inexequible. La expresión declarada exequible queda condicionada al entendido que los niños torerillos únicamente podrán hacer parte de una cuadrilla cuando hayan cumplido los catorce años y, además, los empresarios y las autoridades públicas les garanticen las condiciones de seguridad previstas en los tratados y convenios de derechos internacional suscritos por Colombia, es decir que se le preserven los derechos fundamentales de la niñez, de manera prevalente por su condición de niños. Por otra parte, declara la inconstitucionalidad del artículo 26, que establecía que la presidencia de los espectáculos taurinos corresponderá al alcalde de la localidad. Declara la constitucionalidad del parágrafo del artículo 31 de la ley 916 de 2004, salvo las expresiones "son producto de alto interés nacional, dada su importancia que" y "todos los", las cuales son inexequibles. Declara la constitucionalidad del artículo 80 de la ley demandada, salvo la expresión "fomento de" la cual es inexequible, con lo cual se expulsa del ordenamiento jurídico la posibilidad de que el Estado patrocine el sostenimiento de las escuelas taurinas, aun cuando no los prohíbe. En otras palabras, esta sentencia avanza en la protección de los derechos de los niños que asisten o participan de espectáculos taurinos, así como la prohibición de las entidades públicas de financiar este tipo de actividades.

Ahora bien, la Sentencia C-666 de 2010 resolvió la demanda de inconstitucionalidad contra el artículo 7 (exceptúa el rejoneo, coleo, las corridas de toros, las novilladas, corralejas, becerradas y tientas así, como las riñas de gallos, del régimen contra el maltrato animal) de la ley 84 de 1989 "por la cual se adopta el estatuto nacional de protección de los animales y se crean unas contravenciones”. Como se verá más adelante, este es el caso de mayor importancia y se convierte en el epicentro de esta línea jurisprudencial, pues, con este fallo, la Corte declaró su falta de competencia para desarrollar los límites jurídicos a la protección de los animales, puesto que ésta es una competencia del Congreso de la República. La Corte declaró la constitucionalidad condicionada del artículo 7 de la Ley 84 de 1989 que tiene la excepción que permite la realización de rejoneo, coleo, las corridas de toros, las novilladas, corralejas, becerradas y tientas, pero reitera la prohibición de las entidades públicas de patrocinar o facilitar recursos públicos para su realización ${ }^{31}$. Todo lo anterior, para concluir que la regulación que expida el legislador debe tener en cuenta la obligación de protección a los animales y, en consecuencia, contener una solución que armonice, de forma razonable, con los principios y derechos que justifican la realización de dichas actividades consideradas como manifestaciones culturales. Con este propósito, dicha regulación deberá prever protección contra el sufrimiento y el dolor de los animales empleados en estas actividades y deberá propugnar porque en el futuro se eliminen las conductas especialmente crueles contra ellos o, en ejercicio de su libertad de configuración normativa, puede llegar a prohibir las manifestaciones culturales que implique maltrato animal, si considera que debe primar el deber de protección sobre la excepcionalidad de las expresiones culturales.

Por su parte, la Sentencia C-889 de 2012 resolvió la demanda de inconstitucionalidad contra los artículos 14 (autorización previa para la celebración de espectáculos taurinos) y 15 (comunicación de la realización de espectáculos) ambos parciales de la Ley 916 de 2004. También accionó los requisitos que deben ser verificados por las autoridades locales para autorizar los espectáculos taurinos en plazas de toros permanentes e itinerantes. En esta sentencia, la Corte declara la constitucionalidad de los artículos 17, 18 y 19 de la Ley 916 de 2004, con excepción de la expresión "que requieran autorización previa" contenida en los artículos 17 y 18 citados, que se declara inconstitucional por considerar que el cumplimiento de requisitos legales debe ser igual de riguroso en corridas celebradas en plazas de toros permanentes, así como en aquellas itinerantes. 
El fallo C-283 de 2014 resolvió una demanda de inconstitucionalidad contra los artículos 1 (prohibición de animales en circos, 2 (restricción de emisión de licencias y 3 (adecuación de los espectáculos circenses de la Ley 1638 de 2013. En este asunto, sin embargo, la Corte declaró la constitucionalidad de la ley que prohíbe el empleo de animales en los espectáculos circenses. En este caso, la Corte ponderó entre el respeto a los derechos al trabajo, la libertad de escoger profesión u oficio, el libre desarrollo de la personalidad y la libertad de empresa e iniciativa privada de los trabajadores y propietarios de los circos, y la protección de los animales silvestres en la garantía de la preservación del medio ambiente (deberes constitucionales.

Posteriormente se expidió la Sentencia C-467 de 2016, que resolvió una acción pública de inconstitucionalidad contra la Ley 1774 de 2016, en lo referido a la reforma que hizo del Código Civil, donde declaró a los animales como seres sintientes. Para el accionante, el legislador debió haber ido más allá a partir de instrumentos internacionales retificados en Colombia, y declarar a los animales como sujetos de derecho. En esta ocasión, la Corte declaró la exequibilidad de las disposiciones acusadas, porque:

"si bien es cierto en ellas se alude a los animales como a bienes jurídicos e incluso se emplea la palabra cosas en relación con ellos, también lo es que tal realidad no se opone a la consideración de los animales como seres sintientes dignos de protección contra el maltrato."

En este sentido, la Corte reiteró lo señalado al considerar que las modificaciones introducidas con la aprobación de la Ley 1774 de 2016, en la que se cambió el contenido normativo del artículo 655 del Código Civil, reconoce la calidad de los semovientes como seres sintientes. Para adoptar esa decisión, el Tribunal Constitucional consideró que no cabía hacer un análisis en torno a la pretensión del actor conforme a la cual los animales son titulares de derechos y, en tal calidad, sujetos de protección constitucional contra toda forma de maltrato. Las normas acusadas contienen una regulación de carácter civil, de alcance definitorio, orientado a establecer las condiciones en las cuales los animales pueden ser objeto de relaciones jurídicas, pero no disponen nada en relación con el tratamiento que deban recibir ni con las obligaciones que, de otras normas tanto constitucionales como legales, se derivan para todas las personas en relación con la proscripción del maltrato animal. La sentencia, aunque negó las pretensiones de la demanda, señaló que en la Constitución subyace un deber de protección a los animales en su condición de seres sintientes, que supone un límite derivado de la función ecológica mediante la cual se prohíben tratos crueles.

Las sentencias antes citadas dan cuenta de un avance hacia la protección de tratos crueles a los seres sintientes. Con todo, la sentencia más progresista fue la C-041 de 2017. En este fallo, la Corte decidió la acción pública de inconstitucionalidad que se inició contra la Ley 1774 de 2016 que, entre otras reglas, adicionó el título XI-A, "De los delitos contra los animales", al Código Penal, conservando la excepción a las actividades de rejoneo, coleo, corridas de toros, novilladas, corralejas, becerradas, tientas, riñas de gallos y los procedimientos utilizados en estos espectáculos por considerarlas culturales. Luego de una extensa exposición de las razones por las cuales las prácticas crueles y el espectáculo que se puede derivar de ellas se estarían superando culturalmente, la Corte decidió dar un paso definitivo relativo a la tauromaquia. La Corte señaló:

"[l]a dogmática dinámica y evolutiva impone avanzar con mecanismos más decisivos para la efectividad de los intereses de los animales, al disponer hoy de nuevos estudios científicos y mayores saberes. Es un imperativo repensar posibles horizontes y transformar las sedimentadas tradiciones cuando socavan intereses vitales y primarios de toda sociedad democrática y constitucional." 32

De esta forma se declaró inexequible el parágrafo 3 previsto en el artículo 5 de la Ley 1774 de 2016, que adicionó el artículo 339B al Código Penal, esto es, la excepción al delito de maltrato animal que protegen las prácticas de rejoneo, coleo, las corridas de toros, novilladas, corralejas, becerradas y tientas, así como las riñas de gallos y los procedimientos utilizados en estos espectáculos. No obstante, los efectos del fallo de la Corte se difirieron por dos años, para que el Congreso de la República adaptase la legislación a la jurisprudencia 
constitucional. Esta decisión dio cuenta de una reñida votación y por ello, una clara tensión al interior de la Corte. En efecto, se presentaron cuatro salvamentos de voto y los demás magistrados aclararon su voto.

No obstante, el fallo consignó una estrategia de deserción que planteó una exhortación al Congreso de la República. Con todo, el nuevo balance se hizo sentir en el Auto 547 de 2018 y la Sentencia SU-056 de 2018. Con el citado Auto, la Corte declaró la nulidad de la sentencia C-041 de 2017, un hecho, hasta donde sabemos, inédito en la medida en que fue la primera vez que la Corte declaró la nulidad de una sentencia de constitucionalidad. En este Auto, la Corte consideró que en el fallo del 2017 desconoció el precedente consignado en las sentencias C-666 de 2010 y C-889 de 2012, que remiten la competencia para limitar estas actividades al Congreso de la República, "a través del debate democrático propio de las leyes, sin que ninguna otra autoridad pueda asignarse dicha facultad".

En el marco de este eje jurisprudencial, la Corte Constitucional emitió la Sentencia SU-056 de 2018. En este fallo la Corte tomó una decisión en dos sentidos: primero, decidió por vía de tutela, la constitucionalidad de la consulta popular que el alcalde de Bogotá quería realizar en agosto de 2017 (Decreto Distrital 355 de 2017 y Decreto Distrital 247 de 2017 sobre la prohibición de las corridas de toros en la ciudad; segundo, la competencia del Distrito de Bogotá, como autoridad territorial para ejecutar dicho mandato, en el caso en que efectivamente el voto popular hubiese tomado la decisión de prohibir las corridas de toros en la ciudad. Para la Corte, ninguna de las dos situaciones es constitucionalmente permisible. En concreto, el Tribunal consideró que el funcionario que convoca a una consulta popular debe tener la competencia de ejecutar la decisión del electorado pues éste constituye un mandato popular, y esto no ocurre este caso, en la medida en que la autorización para realizar las corridas de toros en Bogotá viene expresamente dada por el legislador y el órgano administrativo no juega ningún papel en su autorización o prohibición, de acuerdo con lo dispuesto por la Sentencia C-666 de 2010.

\section{El derecho fundamental a la interrupción voluntaria del embarazo}

Por un lado, este eje jurisprudencial ha sido utilizado como un caso control, donde es posible constatar el impacto de las decisiones de la Corte la orientación ideológica y su balance en los magistrados que la componen, y, por el otro, permite evidenciar que ante una línea jurisprudencial consistente, el intento de modificar la línea jurisprudencial puede resultar vencida como consecuencia de las "cascadas de precedentes" con suficiente fuerza gravitacional que impida la regresión en derechos constitucionales.

En efecto, se trata de una línea jurisprudencial estable que tuvo origen en la Sentencia C-355 de 2006, y que desembocó en una línea jurisprudencial progresiva que parece desarrollarse con notable consistencia, por medio de más de veinte sentencias reiterativas, entre las que se destacan los fallos T-946 de 2008, T-388 de 2009, T-585 de 2010, y T-301 de 2016. De este último fallo se resalta la consagración del derecho fundamental de la mujer a la interrupción voluntaria del embarazo como derecho reproductivo, implícito en los derechos fundamentales a la vida digna (artículos 1 y 11 , a la igualdad (artículos 13 y 43, al libre desarrollo de la personalidad (artículo 16, a la información (artículo 20, a la salud (artículo 49 y a la educación (artículo 67, entre otros. Sin embargo, deja de lado el hecho de que el derecho fundamental de la mujer a la interrupción voluntaria del embarazo había quedado subordinado a las condiciones particulares dispuestas en la Sentencia C-355 de 2006. La citada sentencia autorizó el aborto sólo en los casos en que la mujer haya sido víctima de acceso carnal violento o no consentido, cuando está en peligro la vida de la madre y cuando el embrión padece de malformaciones incompatibles con la vida.

No obstante, en el proceso T-6.612.900, la magistrada Cristina Pardo, caracterizada en este trabajo como Conservadora Centro Derecho (CCD presentó una ponencia que pretendía la limitación temporal del derecho a la interrupción voluntaria del embarazo y proponía un giro discursivo al dejar de hablar de la protección del naciturus y sugerir la protección de la vida del que está por nacer. Empero, con una votación de seis en contra de la ponencia y tres a favor, la Corte Constitucional resaltó que existen barreras administrativas 
para las mujeres que acuden a la práctica del aborto legal y exhortó al Congreso para legislar sobre la interrupción voluntaria del embarazo "incluido, si es del caso, el tema de plazos y el aborto libre”, y por medio de la Sentencia T-096 de 2018, decidió conservar las reglas que se habían fijado en la Sentencia C-355 de 2006.

Sin embargo, la magistrada ponente Cristina Pardo pretendía, en una extensa ponencia, limitar el aborto legal hasta la $24^{a}$ semana de gestación. Con todo, un cambio discursivo alertaba una intención restrictiva más profunda, pues en lugar de hablar de la protección debida del que está por nacer, reprochaba al juez de instancia "no proteg[er] la vida del "nasciturus', lo que en otras palabras significaría un nuevo juicio de ponderación, pues no se enfrentaría un derecho fundamental con una protección constitucional, sino la libertad sexual y reproductiva —en caso de delitos sexuales - con un derecho fundamental - la vida del naciturus-. Sobre este punto, la ponencia, posteriormente consignada y resumida en el salvamento de voto, señalaba que:

"En el caso de la causal tercera (pedir la interrupción por violación, incesto, inseminación artificial no consentida o implantación uterina de embrión sin consentimiento, la proporcionalidad y razonabilidad de la medida, tanto por el tiempo de gestación ya transcurrido, como frente al grado de desarrollo del que está por nacer, exigen que la semana 24 sea el límite para la realización de la IVE. [...] No es claro si esa lamentable consideración de la sentencia se debe a la falta de información sobre el significado de la palabra neonato, o si en realidad, se pretende crear un precedente jurisprudencial por el cual se exige al personal médico que considere a quienes tienen secuelas severas orgánicas o funcionales como seres sin vida humana y sin derecho a ella. Sea como sea, una afirmación semejante solo significa un abrupto retroceso en la protección de la vida y la dignidad humana en Colombia, que resulta especialmente grave desde la perspectiva del modelo social de la discapacidad" 33

En su extensa ponencia, la magistrada también sugería que:

"Durante la gestación, la protección de la vida del nasciturus es gradual e incremental y está ligada al desarrollo del feto, de forma que la protección de la vida del nasciturus es entendida como un valor constitucional que logra su mayor protección a partir de la semana 24 de gestación, cuando el feto logra su viabilidad autónoma". ${ }^{34}$

De igual forma, pretendía exigir a la EPS la prestación de servicios de acompañamiento psicológico a las mujeres embarazadas cuando resulten hallazgos de malformación en los exámenes médicos, además, también debían "comunicar estos resultados con objetividad y sin ninguna clase de valoraciones fundadas en paradigmas de discriminación o rechazo contra personas con discapacidad ni en percepciones de su vida como una carga de sufrimiento". En el documento, si la gestación alcanzaba la semana 24, requiere de la realización de un parto inducido y, posterior al nacimiento, exigiría los cuidados médicos o paliativos que requiera el recién nacido como un paciente autónomo.

"La realización de un feticidio en estos casos resulta redundante, arriesgada para la mujer gestante y contraria a derecho. [...] la Corte debió tener en cuenta dos aspectos. El primero es que existe un consenso médico-científico en que, a partir de la semana 24 de gestación se entiende que el feto ha logrado su viabilidad autónoma. El segundo aspecto, relacionado con el primero, es que, como consecuencia de la viabilidad autónoma alcanzada, los protocolos nacionales e internacionales sobre aborto seguro exigen, que previa a la interrupción del embarazo se realice el feticidio (muerte provocada del feto), porque de no hacerlo el feto nacería vivo y la muerte provocada luego del nacimiento se considera homicidio y no aborto".

Con esta frontera, la magistrada sugiere diferenciar entre el derecho fundamental a la interrupción voluntaria del embarazo y el feticidio.

La ponencia fue consignada de manera más resumida en el salvamento de voto de la magistrada. Junto a los argumentos antes señalados, la magistrada ponente ofreció un argumento de legislación comparada con España, Francia, Alemania, Austria, Japón, Chile, Estados Unidos, India, Sudáfrica, México (Distrito Federal), Indonesia, Canadá, Australia (incluidos los ocho Estados que la integran) y Turquía, para ilustrar que en otras prácticas existe un límite de tiempo para interrumpir la gestación.

Ahora bien, en la sentencia citada el magistrado Carlos Bernal, caracterizado en este trabajo como Conservador Centro Derecha (CCD), también salvó su voto. Sin embargo, su postura fue mucho más breve y puntual. Para el magistrado, el juez de instancia violó el derecho de defensa de la accionada al ordenar el aborto 
desde que conoció de la tutela como medida cautelar y supuso una decisión ex ante de la práctica de pruebas necesaria para encontrar acreditada una amenaza inminente de derechos y para establecer el procedimiento médicamente más idóneo. En segundo lugar, apoyando a la magistrada Pardo, consideró que en el caso concreto la condición diagnosticada no era incompatible con la vida y, con ello, se desconoció el precedente de la misma Corte. En tercer lugar, también lo señala el salvamento de voto del magistrado Bernal, el estado avanzado de gestación supuso una carga desproporcionada para la demandada y para el mismo naciturus.

\section{Alteraciones en el peso abstracto y ponderación de Derechos Económicos, Sociales y Culturales (DESC)}

El último eje jurisprudencial versará sobre una estrategia de deserción intrasistémica regresiva en el reconocimiento de la fundamentalidad provisional de los Derechos Económicos, Sociales y Culturales (DESC. Si bien existe nutrida jurisprudencia, con el propósito de probar el argumento de este trabajo, se han seleccionado tres sentencias que permiten constatar la regresión en la protección de los DESC por conexidad y por los valores axiales que subyacen a éstos. Se trata de las sentencias T-091 y T-027 de 2018, que serán contrastadas con la sentencia T-341 de 2016.

En el último fallo citado puede constatarse la realización de un juicio de conexidad más laxo, donde, el derecho a la vivienda digna fue conectado al derecho al ambiente sano y la prevención de desastres. El accionante residía en la vereda El Pedregal del municipio de Tasco, en la finca "El Cucharito", donde existe hace mucho tiempo un nacimiento o manantial de agua del que se abastecen su familia y otras familias del sector. En dicho territorio, la empresa accionada pretende adelantar explotación minera a cielo abierto en la vereda El Pedregal.

En la sentencia T-341 de 2016, la Corte reiteró su jurisprudencia y, en primer lugar, permitió la procedencia de la acción de tutela, a pesar de la existencia de otro medio judicial-acción popular-, en la medida en que la tutela es procedente si con ella se pretende evitar la ocurrencia de un perjuicio irremediable, y segundo, debido a que el mecanismo ordinario de defensa no es idóneo ni eficaz para la protección inmediata y plena de los derechos fundamentales en juego, caso en el cual opera como mecanismo definitivo de protección. Por medio de un amplio recorrido jurisprudencial, la Corte recordó las condiciones para la procedencia de la acción de tutela cuando se desconocen derechos de segunda o tercera generación, a saber:

“i) Que exista conexidad entre la vulneración del derecho colectivo y la violación o amenaza de un derecho fundamental, de tal forma que el daño o amenaza del mencionado derecho sea consecuencia inmediata y directa de la perturbación del derecho colectivo. ii) El demandante debe ser la persona directa o realmente afectada en su derecho fundamental, pues la acción de tutela es de carácter subjetivo. iii) La vulneración o la amenaza del derecho fundamental debe estar plenamente acreditada. iv) La orden judicial que se imparta en estos casos debe orientarse al restablecimiento del derecho de carácter fundamental y 'no del derecho colectivo en sí mismo considerado, pese a que con su decisión resulte protegido, igualmente un derecho de esa naturaleza. v) Adicionalmente, es necesario la comprobación de la falta de idoneidad de la acción popular en el caso concreto." 35

A través de una sentencia sustitutiva, la Corte concedió las pretensiones sin consideraciones sobre los costos o la ejecución material en el que tenían que incurrir los accionados, y por virtud de ello ordenó a la Alcaldía Municipal de Tasco que, en un término no superior a dos meses a partir de la notificación de esta providencia tome las medidas pertinentes y conducentes a la cabal protección del derecho a la vivienda digna de la señora Cenaida Ramos Estupiñán y su familia, procurando la asignación del inmueble dentro del programa de vivienda para damnificados adelantado por el municipio y rendir informe del cumplimiento a la Defensoría del Pueblo (Regional Boyacá) y a la Personería Municipal. La Corte también le ordenó a la empresa Minas Paz del Rio/Votorantim proceder con las adecuaciones técnicas y a dar cumplimiento a los requerimientos de las autoridades ambientales y mineras, tal y como quedó expuesto en la parte motiva de esta providencia, en un tiempo no superior a seis meses, contados a partir de la notificación de esta. La corte determinó que el cumplimiento de esta orden se debería hacer con el 
acompañamiento y mediación de la Alcaldía Municipal de Tasco y de la Personería Municipal de Tasco, al igual que de la Defensoría del Pueblo (Regional Boyacá en el sentido de concientizar a la comunidad de la necesidad de la pronta realización de dichas obras para mitigar los daos ambientales generados. La empresa tuvo que rendir informe cada treinta días al Juzgado Promiscuo Municipal del Distrito Judicial de Santa Rosa de Viterbo sobre el cumplimiento de lo que se ordena y hasta la terminación de las obras en forma satisfactoria.

La sentencia analizada contrasta con los fallos T-027 y T-091 de 2018, donde la Corte parte explícitamente de la necesidad de empezar a ponderar la eficacia de los DESC a la luz de la razonabilidad de la medida de satisfacción exigida al accionado. Así, la Corte determina que la jurisprudencia constitucional, que ha aplicado la ponderación para solucionar colisiones entre derechos y principios fundamentales, ahora debe ser utilizada por el juez constitucional para resolver casos relacionados con la faceta prestacional de los derechos fundamentales, como, por ejemplo, los derechos a la igualdad, al libre desarrollo de la personalidad y la intimidad. Para estos casos, la ponderación también se ofrece como un criterio metodológico racional que permite analizar la relación entre las libertades fundamentales y sus posibles limitaciones.

En el fallo T-027 de 2019 se resolvió la tutela presentada por una estudiante de 45 años y presenta diagnóstico de "hipoacusia neurosensorial severa profunda" con ponencia del Magistrado Carlos Bernal (CCD). Esta condición le permite detectar sonidos a 80 decibeles, lo cual mejora "el acceso a la información y atención de su clase, con apoyo de lectura labiofacial". Si bien la accionante fue incluida dentro del "Registro para la Localización y Caracterización de las Personas con Discapacidad del municipio de Tunja”, y la universidad donde estudiaba adoptó la "Política Institucional de Educación Inclusiva", orientada a "la equiparación de oportunidades de los diversos grupos poblacionales con dificultades en términos de acceso, permanencia y graduación a la educación superior ${ }^{36}$, no contó con acompañamiento ni acciones aafirmativas concretas, lo que "ocasión[ó] inconvenientes a la hora de tomar y desarrollar las clases de tipo presencial'37, exigiendo así, las acciones fácticas positivas que permitiesen la accesibilidad y ayudas técnicas para personas con algún tipo de discapacidad.

De esta manera, a partir del juicio de ponderación antes señalado, la Corte negó algunas de las pretensiones y concedió otras, siguiendo las siguientes premisas:

- El análisis de proporcionalidad debe aplicarse en atención al supuesto de razonabilidad que determine el juez para cada caso concreto. Esto debe analizarse a la luz de los subprincipios de (a) idoneidad, (b) necesidad y (c) proporcionalidad en sentido estricto.

- En relación con la idoneidad, el juez debe verificar que el nivel de satisfacción razonable pretendido (la pretensión del accionante) o las otras alternativas razonables de satisfacción sean adecuados para garantizar el nivel razonable de satisfacción del derecho, de acuerdo con el contenido exigible, previamente analizado.

- La necesidad, por su parte, supone que el juez determine si, en el caso concreto, el nivel de satisfacción razonable pretendido o alguna de las otras alternativas razonables de satisfacción (de todos los medios posibles que permiten satisfacer el nivel razonable y exigible del derecho) son menos lesivas de la razón constitucionalmente legítima que justifica que el obligado no proporcione dicho nivel de satisfacción, sino uno distinto. Sobre este punto, es necesario advertir que, debido a las competencias de las autoridades para definir el contenido de las políticas públicas, la interpretación constitucional debe ser respetuosa del desarrollo normativo realizado por el legislador y por la administración.

- Finalmente, el juicio de proporcionalidad en sentido estricto se debe realizar en atención a la escala tríadica del juicio de ponderación empleado por la jurisprudencia constitucional (leve, medio e intenso). En este sentido, el juez constitucional debe ponderar entre el grado de satisfacción del derecho - ya sea el nivel de satisfacción pretendido u otro distinto-; con respecto a la afectación que se le causaría al obligado a satisfacer el derecho en ese nivel determinado. 
De esta manera, la proporcionalidad se condensa en las siguientes premisas: a) La pretensión del titular del derecho (nivel de satisfacción pretendido); b) La política pública, programa o medida acusada (nivel de satisfacción provisto); c) Razón constitucionalmente legítima para no conceder.

Así, la Corte explicó el nivel razonable de satisfacción del derecho - y, por lo tanto, exigible judicialmente - debe ser: i) razonable, en la medida en que dicho nivel puede adscribirse al contenido del derecho en cuestión; y ii) proporcional, esto es, justificado en que la satisfacción del titular del derecho al recibir el nivel razonable de satisfacción es mayor a la afectación que se le ocasionaría al obligado al exigírsele garantizar dicho nivel razonable de satisfacción. Al final, la Corte negó una de las solicitudes de la accionante (que se garantice el acompañamiento por parte de dos intérpretes a las cátedras y tutorías) en la medida en que consideró que no satisface los subprincipios de necesidad ni proporcionalidad en sentido estricto. En efecto, al contar ya con un intérprete, la pretensión de la accionante compromete, de manera evidente, la autonomía universitaria, la cual está referida a la selección y vinculación del personal universitario y al manejo de sus recursos para el cumplimiento de su misión social y su función institucional. Para la Corte, no recibir el nivel de satisfacción pretendido por la accionante generaría una afectación intensa a la autonomía universitaria, traducida en una grave limitación a su facultad para determinar el manejo de sus recursos para el cumplimiento de su misión social y su función institucional. Asimismo, se generaría un costo previsiblemente alto para la Universidad, que tendría que disponer de mayores recursos para la provisión de un intérprete adicional. Dado lo anterior, esta Sala no concedió la pretensión en los términos pretendidos por la accionante.

Entonces, en este fallo se optó entonces por ponderar un derecho fundamental y un derecho de segunda generación al conceder, finalmente, las siguientes pretensiones: i) facilitar a los intérpretes un material de apoyo básico para aquellas áreas del conocimiento, como derecho, que utilicen lenguaje especializado; y ii) asegurar que los intérpretes puedan tener acceso previo al material y contenidos de las clases que les corresponde interpretar. Asimismo, en caso de considerarlo necesario, podrá: iii) proveer un espacio de capacitación idóneo para que los intérpretes puedan familiarizarse con los contenidos de las áreas de conocimiento a su cargo; y iv) crear estrategias que permitan el diálogo entre docentes e intérpretes, a fin de que estos conozcan los contenidos y vocabulario para contribuir en mejorar la calidad y precisión de la labor de interpretación. Como se observa, la ponderación estuvo fundada en los costos y la inversión de mayores recursos al encontrar en la progresividad de los DESC y sus costos el ámbito de justificación a la restricción del derecho a la educación de la accionante. Como se constata, es una estrategia de deserción intrasistémica que altera el peso abstracto del derecho, y con ello, produce una decisión restrictiva de derechos fundamentales.

La Sentencia T-091 de 2018 nos permite soportar la subhipótesis relativa a la alteración y aplicación de juicios de ponderación que restringen la eficacia de derechos constitucionales. En este asunto, se resolvió la acción de tutela presentada por el Defensor del Pueblo de Curillo-Caquetá en nombre de diez estudiantes de secundaria que habitaban en la vereda Salamina del municipio de Curillo (Caquetá) contra la Oficina de Cobertura Educativa de la Secretaría de Educación Departamental de Caquetá. Dicha institución ofrece servicios de educación básica, que incluyen cinco grados de primaria y cuatro grados de secundaria, pero no ofrece educación media (grados décimo y undécimo). En una respuesta preliminar de la accionada, se negó la solicitud en la medida en que "se acordó que la demanda no era suficiente para la apertura del grado peticionado" ${ }^{38}$. Por ello, los estudiantes y el mismo rector de la Institución Educativa Rural Salamina acudieron a la acción de tutela para el amparo de los derechos fundamentales de los niños.

Siguiendo la misma estrategia de deserción intrasistemémica antes enunciada, la Corte limitó el derecho a la educación de los accionantes. Repitiendo exactamente las cuatro premisas antes citadas, la Corte determinó que, en este caso, la accionada ofrecía una alternativa al grado de satisfacción demandado. De esta manera, si bien la Institución Educativa Rural Salamina no cuenta con los grados décimo y undécimo, quienes deseen cursar el ciclo de educación media lo pueden hacer en la Institución Educativa Rural La Novia, que también está ubicada en el área rural del municipio de Curillo, o en la Institución Educativangel Cuniberti, localizada en el casco urbano, ambas a una distancia razonable de la vereda Salamina. 
Esas instituciones, según lo informado por la Secretaría de Educación Departamental de Caquetá, cuentan con los recursos materiales y humanos necesarios para prestar el servicio educativo en el nivel de formación al que desean ingresar los accionantes. De este modo, la Corte observó que la alternativa era constitucionalmente válida y que la afectación a la accesibilidad que se le causaría a la Secretaría de Educación Departamental de Caquetá es leve. Esto significa que la entidad estaría obligada a garantizarles los cupos a los accionantes, y que, si bien tendría que incurrir en una erogación con el fin de garantizarles el servicio de transporte escolar, esto se enmarca en las opciones que ofrece el ordenamiento jurídico para procurar el acceso material y la permanencia en el sistema educativo.

En este sentido, la Corte ordenó entendió que era razonable que los accionantes cursasen la educación media en la Institución Educativa Rural La Novia o en la Institución Educativa Ángel Cuniberti, pero ordenó a la Secretaría de Educación Departamental de Caquetá garantizar su acceso a una de las instituciones educativas mencionadas, además de proveer de una alternativa más razonable de servicio de transporte escolar, para lo cual deberá tener en cuenta las circunstancias particulares de los accionantes, incluidas sus condiciones socioeconómicas, con el fin de garantizar el componente de accesibilidad material del derecho a la educación.

\section{Conclusiones}

La Corte Constitucional ha encontrado un nuevo balance ideológico que ha tenido un impacto significativo en los ejes jurisprudenciales seleccionados. Como se ha constatado, la concurrencia de un nuevo balance, líneas jurisprudenciales en proceso de consolidación y ejes jurisprudenciales que provocan -o tienen el potencial de provocar - tensiones interinstitucionales o que les subyacen tensiones morales o idiosincráticas, han permitido que, según los fallos analizados, la Corte reduzca o limite la eficacia de derechos fundamentales, participación democrática y protección a los seres sintientes.

No obstante, como se anticipó, este trabajo no pretende abonar a un campo quizá saturado de diagnósticos sobre la politización de la justicia. Al contrario, ha partido de dichos aportes para ofrecer una visión más precisa sobre qué estrategias de deserción intrasistémica permiten materializar las decisiones políticas y posiciones idiosincráticas de los miembros de una Corte.

Esta investigación también plantea una crítica a las tesis instrumentalistas que plantean límites a la capacidad estabilizadora del derecho y del precedente. Como bien lo mostró el análisis realizado a la línea jurisprudencial relativa a la interrupción voluntaria del embarazo, y a pesar de la incorporación de dos magistrados claramente opuestos al mencionado derecho fundamental, la "cascada de precedentes" se impuso sobre el nuevo balance y permitió que prevaleciera la ya reiterada jurisprudencia sobre la materia. Los demás ejes jurisprudenciales corrieron con una suerte distinta, ya que, al final vieron importantes regresiones a partir de un notable revisionismo de la actual Corte Constitucional.

\section{Bibliografía}

2 Boaventura De Sousa Santos \& Mauricio García, El caleidoscopio de las justicias en Colombia: análisis socio-jurídico (Siglo del Hombre Editores, 2001).

Caribe Visible, "Actividad legislativa sobre derechos de los animales", Boletín No. 10 de Caribe Visible, 2015. https://www.uninorte.edu.co/documents/1521176/0/2015+-+Actividad+legislativa+sobre+derechos + de+los+animales/02eb8065-4bd2-4ba6-b604-573c0739be8b?version $=1.2$

Carlos Bernal Pulido, En torno a la legitimidad democrática de la jurisdicción constitucional y la objetividad en el control de constitucionalidad de las leyes, Revista Derecho del Estado, n. ${ }^{\circ}$ 7, 121-140 (1999). https://revistas.uexternad o.edu.co/index.php/derest/article/view/920 
Cass Sunstein, Acuerdos carentes de una teoría completa en derecho constitucional (Universidad ICESI, 2006). http s://doi.org/10.18046/prec.v0.1423

Corte Constitucional de Colombia. Sentencia C-035 de 2016 (M. P. Gloria Stella Ortiz Delgado; 8 de febrero de 2016).

Corte Constitucional de Colombia. Sentencia C-041 de 2017 (M. P. Gabriel Eduardo Mendoza Martelo y Jorge Iván Palacio Palacio; 1 de febrero de 2017).

Corte Constitucional de Colombia. Sentencia C-053 de 2019 (M. P. Cristina Pardo Schlesinger; 13 de febrero de 2019).

Corte Constitucional de Colombia. Sentencia C-123 de 2014 (M. P. Alberto Rojas Ríos; 5 de marzo de 2014).

Corte Constitucional de Colombia. Sentencia C-273 de 2016 (M. P. Gloria Stella Ortiz Delgado; 25 de mayo de 2016).

Corte Constitucional de Colombia. Sentencia SU-095 de 2018 (M. P. Cristina Pardo Schlesinger; 11 de octubre de 2018).

Corte Constitucional de Colombia. Sentencia T-027 de 2019 (M. P. Alberto Rojas Ríos; 30 de enero de 2019).

Corte Constitucional de Colombia. Sentencia T-091 de 2018 (M. P. Carlos Bernal Pulido; 9 de marzo de 2018).

Corte Constitucional de Colombia. Sentencia T-096 de 2018 (M. P. Luis Guillermo Guerrero Pérez; 20 de marzo de 2018).

Corte Constitucional de Colombia. Sentencia T-121 de 2017 (M. P. Luis Ernesto Vargas Silva; 27 de febrero de 2017).

Corte Constitucional de Colombia. Sentencia T-341 de 2016 (M. P. Gabriel Eduardo Mendoza Martelo; 29 de junio de 2016).

Corte Constitucional de Colombia. Sentencia T-445 de 2016 (M. P. Antonio José Lizarazo; 19 de agosto de 2016).

Diego Eduardo López Medina, El derecho de los jueces: obligatoriedad del precedente constitucional, análisis de sentencias y líneas jurisprudenciales y teoría del derecho judicial (Legis, 2006).

Eduardo Oteiza, La Corte Suprema: entre la justicia sin política y la política sin justicia (Librería Editora Platense, 2010).

Gretchen Helmke \& Julio Ríos-Figueroa, Courts in Latin America (Cambridge, 2013).

Jorge Esquirol, Las ficciones del derecho latinoamericano (Siglo del Hombre, 2014).

Juan Pablo Sarmiento E., La justicia administrativa entre dictaduras. Una crítica a la construcción del derecho administrativo en Colombia (Uniandes, 2017).

Mario Alberto Cajas Sarria, La justicia constitucional del General Gustavo Rojas Pinilla: entre el Tribunal de Garantias Constitucionales y la Sala de Negocios Constitucionales. Colombia, 1953-1957, Revista de Historia Constitucional, n. ${ }^{\circ} 17,273-307$ (2016). https://www.redalyc.org/pdf/2590/259046967012.pdf

Miguel Malagón Pinzón, El control de constitucionalidad y de legalidad ejercido por el poder legislativo (1811-1842), Revista Digital de Derecho Administrativo, n. ${ }^{\circ} 6,11-24$ (2011). https://revistas.uexternado.edu.co/index.php /Deradm/article/view/3078

Rachel Sieder, Line Schjolden \& Alan Angell (eds.), the Judicialization of Politics in Latin America (Palgrave MacMillan, 2005).

Sebastián Linares, La (i)legitimidad democrática del control judicial de las leyes (Marcial Pons, 2008). 


\section{Anexo 1.}

Caracterización de la posición ideológica de los magistrados de la Corte Constitucional, con períodos y nominación

\begin{tabular}{|c|c|c|c|c|}
\hline Magistrado & \multicolumn{2}{|c|}{ Período } & \multirow{2}{*}{$\begin{array}{c}\text { Orientación } \\
\text { ideológica } \\
\text { Liberal centro } \\
\text { derecha }\end{array}$} & \multirow{2}{*}{\begin{tabular}{|l|} 
Postulante \\
\\
\end{tabular}} \\
\hline Alejandro Linares Cantillo & $\begin{array}{l}\text { Diciembre de } \\
2015\end{array}$ & $\begin{array}{l}\text { Diciembre de } \\
2023\end{array}$ & & \\
\hline Mauricio González Cuervo & $\begin{array}{l}\text { Octubre de } \\
2007\end{array}$ & $\begin{array}{l}\text { Octubre de } \\
2015\end{array}$ & $\begin{array}{c}\text { Conservador centro } \\
\text { derecha }\end{array}$ & \multirow{3}{*}{ 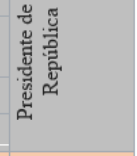 } \\
\hline Álvaro Tafur Galvis & Julio de 1999 & Julio de 2007 & Centro progresista & \\
\hline Hernando Herrera Vergara & Marzo de 1993 & Enero de 1999 & Centro Liberal & \\
\hline Gloria Stella Qrtíz Delgado & Julio de 2014 & Julio de 2022 & $\begin{array}{c}\text { Centro Progresista- } \\
\text { católica }\end{array}$ & \multirow{4}{*}{ 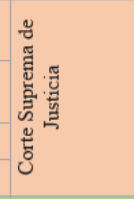 } \\
\hline Nilson Pinilla Pinilla & Junio de 2006 & Junio de 2014 & $\begin{array}{l}\text { Conservador centro } \\
\text { derecha-católico }\end{array}$ & \\
\hline Alfredo Beltrán Sierra & Junio de 1998 & Junio de 2006 & Centro progresista & \\
\hline Jorge Arango Mejía & Marzo de 1991 & Abril de 1998 & Centro progresista & \\
\hline Luis Guillermo Guerrero Pérez & $\begin{array}{l}\text { Septiembre de } \\
2012\end{array}$ & $\begin{array}{l}\text { Septiembre de } \\
2020\end{array}$ & $\begin{array}{l}\text { Conservador centro } \\
\text { derecha-católico }\end{array}$ & \multirow{4}{*}{ 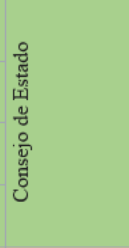 } \\
\hline Juan Carlos Henao & $\begin{array}{l}\text { Febrero de } \\
2009\end{array}$ & Abril de 2012 & Centro progresista & \\
\hline Jaime Araujo Rentería & Marzo de 2001 & $\begin{array}{l}\text { Febrero de } \\
2009\end{array}$ & Centro progresista & \\
\hline Carlos Gaviria Díaz. & Marzo de 1993 & $\begin{array}{l}\text { Febrero de } \\
2001\end{array}$ & Centro progresista & \\
\hline Alberto Rojas Ríos & Mayo de 2013 & Mayo de 2021 & $\begin{array}{l}\text { Conservador- } \\
\text { progresista }\end{array}$ & \multirow{4}{*}{ 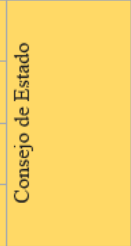 } \\
\hline Humberto Antonio Sierra Porto & $\begin{array}{l}\text { Septiembre de } \\
2004\end{array}$ & $\begin{array}{c}\text { Septiembre de } \\
2012\end{array}$ & Centro progresista & \\
\hline $\begin{array}{l}\text { Luis Eduardo Montealegre } \\
\text { Lynete }\end{array}$ & Enero de 2001 & Mayo de 2004 & $\begin{array}{l}\text { Conservador- } \\
\text { progresista }\end{array}$ & \\
\hline Antonio Barrera Carbonell & Marzo de 1993 & $\begin{array}{l}\text { Octubre de } \\
2001\end{array}$ & Centro progresista & \\
\hline Antonio José Lizarazo Ocampo & $\begin{array}{l}\text { Febrero de } \\
2017\end{array}$ & $\begin{array}{l}\text { Febrero de } \\
\quad 2025\end{array}$ & Centro liberal & \multirow{4}{*}{ 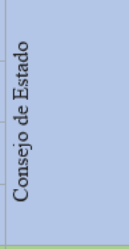 } \\
\hline $\begin{array}{l}\text { Gabriel Eduardo Mendoza } \\
\text { Martelo, Periodo }\end{array}$ & $\begin{array}{l}\text { Febrero de } \\
2009\end{array}$ & $\begin{array}{l}\text { Febrero de } \\
2017\end{array}$ & $\begin{array}{l}\text { Conservador } \\
\text { progresista }\end{array}$ & \\
\hline Rodrigo Escobar Gil & $\begin{array}{l}\text { Febrero de } \\
2001\end{array}$ & Enero de 2009 & $\begin{array}{c}\text { Conservador centro } \\
\text { derecha }\end{array}$ & \\
\hline Vladimiro Naranjo Mesa & Marzo de 1993 & $\begin{array}{l}\text { Febrero de } \\
\quad 2001\end{array}$ & $\begin{array}{l}\text { Conservador centro } \\
\text { derecha-católico }\end{array}$ & \\
\hline Cristina Pardo Schlesinger & Mayo de 2017 & Mayo de 2025 & $\begin{array}{l}\text { Conservador centro } \\
\text { derecha-católica }\end{array}$ & 㤩可导者。 \\
\hline Jorge Pretelt Chaljub & Marzo de 2009 & $\begin{array}{l}\text { Marzo de } \\
2017\end{array}$ & $\begin{array}{c}\text { Conservador centro } \\
\text { derecha }\end{array}$ & \multirow{7}{*}{  } \\
\hline Marco Gerardo Monroy Cabra & Marzo de 2001 & $\begin{array}{l}\text { Febrero de } \\
2009\end{array}$ & Centro conservador & \\
\hline Alejandro Martínez Caballero & $\begin{array}{c}\text { Noviembre de } \\
1991\end{array}$ & $\begin{array}{l}\text { Febrero de } \\
\quad 2001\end{array}$ & Centro progresista & \\
\hline Carlos Libardo Bernal Pulido & Mayo de 2017 & Mayo de 2025 & $\begin{array}{c}\text { Conservador centro } \\
\text { derecha-cristiana }\end{array}$ & \\
\hline María Victoria Calle & Abril 2009 & Abril 2017 & Centro progresista & \\
\hline Manuel José Cepeda Espinosa & $\begin{array}{c}\text { Febrero de } \\
2001\end{array}$ & Enero de 2009 & Centro progresista & \\
\hline Eduardo Cifuentes Muñoz & $\begin{array}{l}\text { Noviembre de } \\
1991\end{array}$ & $\begin{array}{l}\text { Agosto de } \\
2000\end{array}$ & Centro progresista & \\
\hline Diana Fajardo Rivera & $\begin{array}{l}6 \text { de junio de } \\
2017\end{array}$ & $\begin{array}{l}6 \text { de junio de } \\
2025\end{array}$ & Centro progresista & \multirow{4}{*}{ 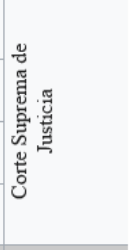 } \\
\hline Luis Ernesto Vargas Silva & $\begin{array}{l}\text { Febrero de } \\
2009\end{array}$ & $\begin{array}{l}\text { Febrero de } \\
2017\end{array}$ & Centro progresista & \\
\hline Jaime Córdoba Triviño & Marzo de 2001 & $\begin{array}{l}\text { Febrero de } \\
2009\end{array}$ & Centro progresista & \\
\hline $\begin{array}{l}\text { José Gregorio Hernández } \\
\text { Galindo }\end{array}$ & $\begin{array}{l}\text { Diciembre de } \\
\quad 1991\end{array}$ & $\begin{array}{l}\text { Febrero de } \\
2001\end{array}$ & $\begin{array}{c}\text { Conservador centro } \\
\text { derecha }\end{array}$ & \\
\hline José Fernando Reyes Cuartas & $\begin{array}{c}5 \mathrm{de} \\
\text { septiembre de } \\
2017\end{array}$ & $\begin{array}{c}5 \mathrm{de} \\
\text { septiembre de } \\
2025\end{array}$ & $\begin{array}{c}\text { Conservador centro } \\
\text { derecha }\end{array}$ & \multirow{4}{*}{ 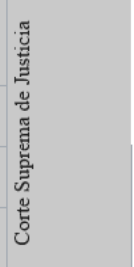 } \\
\hline Jorge Iván Palacio Palacia & Marzo de 2009 & $\begin{array}{l}\text { Febrero de } \\
2017\end{array}$ & Centro progresista & \\
\hline Clara Inés Vargas Hernández & Marzo de 2001 & $\begin{array}{l}\text { Febrero de } \\
2009\end{array}$ & Centro progresista & \\
\hline Fabio Morón Díaz & $\begin{array}{c}\text { Noviembre de } \\
1991\end{array}$ & $\begin{array}{l}\text { Febrero de } \\
2001\end{array}$ & Centro progresista & \\
\hline
\end{tabular}

Fuente: elaboración propia 


\section{Notas}

* Artículo de investigación. El autor pertenece al Grupo de Derecho y Ciencia Política (GIDECP) de la Universidad del Norte.

1 Ver Gretchen Helmke \& Julio Ríos-Figueroa, Courts in Latin America (Cambridge, 2013); Rachel Sieder, Line Schjolden \& Alan Angell (eds.), The Judicialization of Politics in Latin America (Palgrave MacMillan, 2005); Eduardo Oteiza, La Corte Suprema: entre la justicia sin política y la política sin justicia (Librería Editora Platense, 2010); Jorge Esquirol, Las ficciones del derecho latinoamericano (Siglo del Hombre, 2014); Mario Alberto Cajas Sarria, La justicia constitucional del General Gustavo Rojas Pinilla: entre el Tribunal de Garantías Constitucionales y la Sala de Negocios Constitucionales. Colombia, 1953-1957, Revista de Historia Constitucional, n. ${ }^{\circ}$ 17, 273-307 (2016); Juan Pablo Sarmiento E., La justicia administrativa entre dictaduras. Una crítica a la construcción del derecho administrativo en Colombia (Uniandes, 2017).

2 Diego Eduardo López Medina, El derecho de los jueces: obligatoriedad del precedente constitucional, análisis de sentencias y líneas jurisprudenciales y teoría del derecho judicial (Legis, 2006).

3 Mario Alberto Cajas Sarria, op. cit.

4 Ver, por ejemplo: Carlos Bernal Pulido, En torno a la legitimidad democrática de la jurisdicción constitucional y la objetividad en el control de constitucionalidad de las leyes, Revista Derecho del Estado, n. ${ }^{\circ}$, 121-140 (1999).

5 Miguel Malagón Pinzón, El control de constitucionalidad y de legalidad ejercido por el poder legislativo (1811-1842), Revista Digital de Derecho Administrativo, n. ${ }^{\circ}$ 6, 11-24 (2011).

6 Juan Pablo Sarmiento E., op. cit.

7 Sebastián Linares, La (i)legitimidad democrática del control judicial de las leyes (Marcial Pons, 2008).

82 Boaventura De Sousa Santos \& Mauricio García, El caleidoscopio de las justicias en Colombia: análisis socio-jurídico (Siglo del Hombre Editores, 2001).

9 Cass Sunstein, Acuerdos carentes de una teoría completa en derecho constitucional (Universidad ICESI, 2006).

10 La Cascada informativa, afirma Sunstein, releva al sujeto que emitirá su opinión o tomará una decisión de pensar por medio de su propia información o de opiniones privadas. Al contrario, en la medida en que se tienen esas bases comportamentales, la tendencia a repetir o incorporar la experiencia acumulada será alta, reproduciendo así el comportamiento de los antecesores. En este sentido, la predicción, sea institucional o individual, se hace una tarea incontestable y quizá superior a sus inclinaciones políticas o a sus competencias. Cass Sunstein, op. cit.

11 Mario Alberto Cajas Sarria, op. cit.

12 Diego Eduardo López Medina, op. cit.

13 Este título contó con el aporte de las estudiantes Paulina Buitrago Cueto y Camila Palmeth Betancourt, en la solicitud de nulidad contra la Sentencia SU-095 de 2018 presentada en el Exp: T-6298958, ante la Corte Constitucional.

14 Corte Constitucional de Colombia. Sentencia T-445 de 2016 (M. P. Antonio José Lizarazo; 19 de agosto de 2016).

15 Corte Constitucional de Colombia. Sentencia C-123 de 2014 (M. P. Alberto Rojas Ríos; 5 de marzo de 2014).

16 Íd.

17 Íd.

18 Íd.

19 Corte Constitucional de Colombia. Sentencia T-445 de 2016 (M. P. Antonio José Lizarazo; 19 de agosto de 2016).

20 Íd.

21 Íd.

22 Íd.

23 Íd.

24 Íd.

25 Corte Constitucional de Colombia. Sentencia C-123 de 2014 (M. P. Alberto Rojas Ríos; 5 de marzo de 2014).

26 Íd.

27 Íd.

28 El citado artículo disponía: "Cuando el desarrollo de proyectos de naturaleza turística, minera o de otro tipo, amenace con crear un cambio significativo en el uso del suelo, que dé lugar a una transformación en las actividades tradicionales de un municipio, se deberá realizar una consulta popular de conformidad con la ley. La responsabilidad de estas consultas estará a cargo del respectivo municipio. Parágrafo. En todo caso, las decisiones sobre el uso del suelo deben ser aprobadas por el Concejo Municipal".

29 Este título recoge algunos aportes de Emilio Aguilar Gómez, en su trabajo sobre "Actividad legislativa sobre derechos de los animales", Boletín No. 10 de Caribe Visible, 2015.

30 Artículo $1^{\circ}$. de la Ley 916 de 2004 
31 La Corte condicionó la constitucionalidad de la citada norma en el siguiente sentido: "1) Que la excepción allí planteada permite, hasta determinación legislativa en contrario, si ello llegare a ocurrir, la práctica de las actividades de entretenimiento y de expresión cultural con animales allí contenidas, siempre y cuando se entienda que estos deben, en todo caso, recibir protección especial contra el sufrimiento y el dolor durante el transcurso de esas actividades. En particular, la excepción del Artículo 7 de la Ley 84 de 1989 permite la continuación de expresiones humanas culturales y de entretenimiento con animales, siempre y cuando se eliminen o morigeren en el futuro las conductas especialmente crueles contra ellos en un proceso de adecuación entre expresiones culturales y deberes de protección a la fauna. 2) Que únicamente podrán desarrollarse en aquellos municipios o distritos en los que las mismas sean manifestación de una tradición regular, periódica e ininterrumpida y que por tanto su realización responda a cierta periodicidad; 3) que sólo podrán desarrollarse en aquellas ocasiones en las que usualmente se han realizado en los respectivos municipios o distritos en que estén autorizadas; 4) que sean estas las únicas actividades que pueden ser excepcionadas del cumplimiento del deber constitucional de protección a los animales; y 5) que las autoridades municipales en ningún caso podrán destinar dinero público a la construcción de instalaciones para la realización exclusiva de estas actividades".

32 Corte Constitucional de Colombia. Sentencia C-041 de 2017 (M. P. Gabriel Eduardo Mendoza Martelo y Jorge Iván Palacio Palacio; 1 de febrero de 2017).

33 Corte Constitucional de Colombia. Salvamento de voto a la Sentencia T-096 de 2018 (M.P. Luis Guillermo Guerrero Pérez; 20 de marzo de 2018)

34 Íd.

35 Corte Constitucional de Colombia. Sentencia T-341 de 2016 (M. P. Gabriel Eduardo Mendoza Martelo; 29 de junio de 2016).

36 Corte Constitucional de Colombia. Sentencia T-027 de 2019 (M. P. Alberto Rojas Ríos; 30 de enero de 2019).

37 Íd.

38 Corte Constitucional de Colombia. Sentencia T-091 de 2018 (M. P. Carlos Bernal Pulido; 9 de marzo de 2018). 